\title{
O capital financeiro no comando: uma análise da trajetória acadêmico-profissional dos principais membros da equipe econômica do governo FHC (1995/2002)
}

\author{
Rafael Vaz da Motta Brandão ${ }^{1}$
}

\begin{abstract}
Resumo: $\mathrm{O}$ artigo tem como objetivo realizar um levantamento da trajetória acadêmica e profissional dos principais nomes da equipe econômica do governo FHC (1995/2002), ao mesmo tempo em que se propõe a fazer um mapeamento dos responsáveis pela elaboração e execução do projeto de reforma do Estado alinhado com as principais diretrizes do neoliberalismo e com os interesses do capital financeiro. Entre eles, estavam burocratas, economistas, empresários e banqueiros, responsáveis pelo estabelecimento de relações estreitas com grupos econômicos nacionais e estrangeiros, transitando livremente entre o setor "público" e o setor privado.
\end{abstract}

Palavras-chaves: Economistas. Banqueiros. Equipe Econômica. Neoliberalismo. Governo FHC.

\section{The financial capital in charge: an analysis of the academic- professional trajectory of the main members of the economic team of the government FHC (1995/2002)}

\begin{abstract}
The article aims to carry out a survey of the academic and professional trajectory of the main names of the economic team of the FHC government (1995/2002), at the same time as it proposes to map the responsible for the elaboration and execution of the reform project of the state aligned with the main guidelines of neoliberalism and the interests of financial capital. Among them were bureaucrats, economists, entrepreneurs and bankers, who were responsible for establishing close relations with national and foreign economic groups, moving freely between the "public" sector and the private sector.
\end{abstract}

Keywords: Economists. Bankers. Economic Team. Neoliberalism. Government FHC.

Embora o governo FHC tivesse um projeto claro e relativamente coeso, estruturado em torno do ajuste da economia brasileira ao modelo neoliberal, isso não significava que os diversos grupos que o integraram não apresentassem diferenças entre

\footnotetext{
${ }^{1}$ Professor visitante do Departamento de Ciências Humanas e do Programa de Pós-Graduação em História Social da Universidade do Estado do Rio de Janeiro, Faculdade de Formação de Professores (UERJ-FFP). Doutor em História Social pela Universidade Federal Fluminense (UFF). E-mail para contato: rafabrandao@uol.com.br.
} 
si. Podemos identificar, pelo menos, dois grandes grupos distintos que disputavam a hegemonia dentro do governo: o primeiro, o grupo do PSDB paulista, tinha como principal base de apoio o empresariado industrial paulista e nacional; e o segundo, formado pelo chamado grupo dos economistas-banqueiros, estruturados em torno do departamento de Economia da PUC-RJ e fortemente ligado ao capital financeiro. É centrado no estudo da trajetória acadêmica e profissional dos principais nomes deste segundo grupo que este artigo tem como principal objetivo.

É importante destacar que esta disputa não se dava em relação ao conteúdo geral do projeto de reforma do Estado, uma vez que importantes quadros do PSDB paulista, como José Serra, Luis Carlos Bresser Pereira, Luis Carlos Mendonça de Barros e Sérgio Motta, homens ligados ao empresariado nacional, dedicaram-se intensamente à tarefa da abertura econômica e da privatização de empresas estatais. No entanto, na condução do projeto, há questões de método, critérios, ênfase, prioridades de interesses, que vão se constituir em diferenças importantes entre estes dois grupos, gerando, muitas vezes, fissuras dentro do próprio aparelho estatal ${ }^{2}$.

Não resta dúvida de que o grupo dos economistas-banqueiros exerceu maior influência sobre a política econômica do governo FHC, tendo ocupado postos chaves nas principais agências estatais da área, como o ministério da Fazenda, o Banco Central (BC) e o BNDES. Este grupo era extremamente articulado com a banca internacional, tendo livre entrada em organismos financeiros como o Banco Mundial, o BID e o FMI. Organizou-se, fundamentalmente, em torno do departamento de Economia da PUC-RJ e de seu curso de pós-graduação, cujos pioneiros foram Edmar Bacha e Francisco Lopes, e do qual também foram professores Pedro Malan, Pérsio Arida, Gustavo Franco, André Lara Resende, Edward Amadeo e Winston Fritsch. Armínio Fraga e Elena Landau foram

\footnotetext{
2 As maiores divergências se davam em relação ao papel conferido à utilização dos recursos das privatizações das estatais brasileiras. O ministro da Fazenda, Pedro Malan, defendia a utilização do dinheiro para o pagamento da dívida pública, enquanto que outros ministros, entre eles, José Serra, do Planejamento, e Sérgio Motta, das Comunicações, eram favoráveis à aplicação destes recursos na retomada do desenvolvimento econômico através de investimentos do BNDES. Com a saída de Serra da pasta do Planejamento, Malan acabaria vencendo a disputa interna, convencendo FHC da necessidade de redução do déficit público através das privatizações. Outro ponto de discordância entre os dois grupos deu-se em relação à participação do capital estrangeiro no setor bancário. Logo nos primeiros meses do governo FHC, enquanto que a equipe do BC e o ministro Malan defendiam a abertura do setor e a participação de grupos estrangeiros nas privatizações dos bancos estaduais, José Serra entendia que a abertura do setor bancário deveria ser gradual e melhor estudada.
} 
Revista NEP, Núcleo de Estudos Paranaenses, Curitiba, v.4, n.2, dez. 2018

alunos de John Williamson, o principal organizador do encontro promovido pelo Institute for International Economics em novembro de 1989 e que cunhou a expressão "consenso de Washington”, na PUC-RJ no final dos anos 70 e início da década de 1980.

Este grupo teve papel de destaque na elaboração do Plano Real, que garantiu a vitória eleitoral de FHC. Outro traço característico dos economistas-banqueiros é que praticamente todos os seus integrantes fizeram doutorado nos EUA, predominantemente em Harvard (Francisco Lopes, Gustavo Franco, Eleazar de Carvalho Filho e Edward Amadeo), no MIT (Pérsio Arida, Eliana Cardoso e André Lara Resende) e em Berkeley (Pedro Malan e Paolo Zaghen). Edmar Bacha obteve o doutorado em Yale e Armínio Fraga, em Princeton. Estas universidades, junto com outros centros de ensino norteamericanos, como a universidade de Chicago, formaram os quadros de intelectuais orgânicos do pensamento neoliberal, implantado enquanto política econômica em quase todos os países da América Latina nos anos 90.

Além de serem os responsáveis pela execução de um modelo econômico amplamente desfavorável à maioria da população brasileira, outro traço marcante deste grupo, era o fato de que seus integrantes trafegavam livremente entre altos cargos do setor público e do setor privado, sobretudo, na área financeira. Nesse caminho, seja prestando serviços de "consultoria", seja integrando conselhos de administração, levavam consigo informações privilegiadas para a atividade privada, favorecendo os interesses do grande capital como no caso dos processos de privatizações.

Um dos principais nomes do grupo dos economistas-banqueiros, Pedro Malan ${ }^{3}$ ocupou o cargo de ministro da Fazenda durante os oitos anos do governo FHC. Em 1963, formou-se em engenharia elétrica pela PUC-RJ, instituição da qual também foi professor. Em outubro de 1966, após concluir curso na CEPAL, ingressou no Escritório de Pesquisa Econômica Aplicada (EPEA), vinculado ao ministério do Planejamento. Em 1973, fez doutorado em Economia na universidade de Berkeley (EUA).

\footnotetext{
3 Dicionário Histórico-Biográfico Brasileiro, CPDOC, verbete Pedro Malan; PICCOLO, Monica. Reformas Neoliberais no Brasil: a privatização nos governos Fernando Collor e Fernando Henrique Cardoso. (Doutorado em História). Programa de Pós-Graduação em História da Universidade Federal Fluminense, Niterói, 2010, p. 307-309; "Quem é quem no governo". In: Caros Amigos Reportagem Oficinas de Informações, dezembro de 1998.
} 
Revista NEP, Núcleo de Estudos Paranaenses, Curitiba, v.4, n.2, dez. 2018

Em 1983, assumiu o cargo de diretor da Divisão de Análise de Políticas e Pesquisas do Centro de Empresas Transnacionais da ONU, em Nova Iorque. Dois anos depois, tornou-se diretor do departamento de Economia Internacional e Assuntos Sociais da ONU e, em 1986, foi indicado pelo ministro do Planejamento do governo Sarney, João Sayad, e pelo presidente do BC, Fernão Bracher, para exercer o cargo de diretor-executivo do Brasil no Banco Mundial. No governo Collor, deixou o Banco Mundial para assumir, em julho de 1990, a diretoria-executiva do Brasil junto ao Banco Interamericano de Desenvolvimento (BID). Em junho do ano seguinte, foi nomeado negociador-chefe da dívida externa brasileira em Washington, ficando no cargo até agosto de 1993. Neste período, Malan foi o principal responsável pela negociação da dívida externa brasileira com os credores internacionais nos termos do Plano Brady ${ }^{4}$.

Em agosto de 1993, indicado por FHC, então ministro da Fazenda do governo Itamar Franco, assumiu a presidência do BC. Com a vitória tucana nas eleições de 1994, Pedro Malan foi convidado a ocupar o ministério da Fazenda, sendo o seu titular nos oito anos seguintes em que FHC esteve no poder ${ }^{5}$. Desde que assumiu a pasta, Malan defendeu a reforma do Estado, sendo um dos principais defensores das privatizações como forma de reduzir o déficit público. Deixou o ministério da Fazenda, sendo sucedido por Antônio Palocci, no governo Lula da Silva.

A partir de então, Malan passou a exercer uma longa trajetória no setor privado. Em abril de 2003, tornou-se vice-presidente do conselho de administração do Unibanco. Em 2008, passou a membro independente do conselho de administração da OGX Petróleo e Gás, do grupo EBX, de Eike Batista. Também integravam o conselho, Francisco Gros (ex-presidente do BNDES) e Eliezer Batista (pai de Eike Batista, ex-presidente da Vale do Rio Doce e ex-ministro das Minas e Energia no governo João Goulart). Ainda em 2008, quando ocorreu a fusão entre Itaú e Unibanco, foi o primeiro presidente do conselho consultivo internacional do Itaú-Unibanco. Em 2009, integrou o conselho de

\footnotetext{
${ }^{4}$ O Plano Brady é o nome dado ao plano de reestruturação da dívida externa de países em desenvolvimento - especialmente da América Latina - lançado em 1989, pelo secretário do Tesouro dos EUA, Nicholas Brady. O plano permitia a renegociação da dívida destes países mediante a troca por novos bônus. Em contrapartida, seus governos deveriam promover uma série de reformas liberalizantes em seus mercados. ${ }^{5}$ Pedro Malan foi o segundo ministro da Fazenda que mais tempo esteve à frente da pasta, perdendo apenas para Artur de Souza Costa, que permaneceu onze anos no cargo durante o governo Vargas, entre 1934 e 1945.
} 
administração da EDP do Brasil, empresa do setor de energia controlada pela EDP de Portugal e que participou do consórcio que comprou a CERJ, em 1996.

Malan publicou diversos estudos e artigos em revistas nacionais e estrangeiras e livros, entre eles, Política econômica externa e industrialização no Brasil, de 1977, em coautoria com Regis Bonelli, Marcelo de Paiva Abreu e José Eduardo Pereira, e Política econômica e teorias de balanço de pagamentos, em 1981. Sua filha, Cecília Malan, é jornalista do grupo Globo, trabalhando na sucursal em Londres, e sua esposa, Catarina Gontijo, é sócia, na Editora 34, de Bia Bracher, filha do banqueiro Fernão Bracher ${ }^{6}$, fundador, junto com Pérsio Arida e Edmar Bacha, do BBA-Creditanstlat, em associação com o capital austríaco. Bracher foi presidente do BC no governo Sarney e é tido como um dos principais formuladores do Plano Real.

Pérsio Arida $^{7}$ foi o primeiro dos quatro presidentes do BC no governo FHC. Nascido em 1952, no início dos anos 70, ainda estudante secundarista, participou em São Paulo de movimentos clandestinos de oposição ao regime militar. Preso e torturado, Arida foi denunciado, em 1971, por subversão e participação na organização Vanguarda Armada Revolucionária Palmares (VAR-Palmares).

Formado em Economia pela USP em 1975, foi professor convidado nos EUA, tendo lecionado no Institute for Advanced Study (1978/1979) e no Smithsonian Institution (1984/1985). Na década de oitenta foi professor da PUC-RJ e, em conjunto com André Lara Resende, seu colega no departamento de Economia, escreveu o artigo Inertial inflation and monetary reform in Brazil, que foi originalmente apresentado em Washington, em dezembro de 1984, em um seminário promovido pelo Institute for International Economics, a mesma instituição que organizou o encontro que estabeleceu o chamado "consenso de Washington". O artigo de Arida e Lara Resende é considerado a principal base teórica para os sucessivos planos econômicos adotados no Brasil, incluindo o Plano Real. Em 1992, concluiu o doutorado em Economia pelo Massachusetts Institute of Technology (MIT).

\footnotetext{
6 Dicionário Histórico-Biográfico Brasileiro, CPDOC, verbete Fernão Bracher; "Quem é quem no governo". In: Caros Amigos Reportagem- Oficinas de Informações, dezembro de 1998.

${ }^{7}$ Dicionário Histórico-Biográfico Brasileiro, CPDC, verbete Pérsio Arida; PICCOLO, Monica. Reformas Neoliberais... Op. cit., p. 320-322; "Quem é quem no governo". In: Caros Amigos Reportagem - Oficinas de Informações, dezembro de 1998.
} 
Revista NEP, Núcleo de Estudos Paranaenses, Curitiba, v.4, n.2, dez. 2018

Em 1985, durante o governo José Sarney, Arida foi secretário da Coordenação Econômica Social. No ano seguinte, tornou-se diretor da área bancária do BC, sendo um dos responsáveis pelo Plano Cruzado.

Ao deixar o Banco Central, em 1987, Arida passou a atuar no setor privado. Naquele ano, foi convidado para ser diretor da Brasil Warrant, empresa que controlava os negócios da família Moreira Salles (Unibanco), onde ficou até 1989. Ao mesmo tempo, foi sócio e diretor da HE Participações. Em junho de 1988, porém, desligou-se da empresa para assumir uma das vice-presidências do Unibanco. Em 1988, fundou, juntamente com Fernão Bracher e Edmar Bacha, o banco BBA-Creditanstalt, em associação com o Bank Austria Creditanstalt, maior grupo financeiro da Áustria.

No início da década de noventa, filiou-se ao PSDB. Foi indicado pelo então presidente Itamar Franco e por FHC para ocupar a presidência do BNDES. Arida assumiu o cargo em setembro de 1993 e seu ingresso na equipe econômica do governo foi anunciado como um reforço na execução do programa de privatizações. Enquanto presidente do BNDES, Arida foi também um dos principais idealizadores do Plano Real, anunciado ainda no governo Itamar.

No início do governo FHC, foi convidado para substituir Pedro Malan no BC. Entretanto, permaneceu apenas cinco meses à frente do posto. A austeridade na administração do dinheiro público, a manutenção das elevadas taxas de juros, somadas a sua posição incisiva em relação à privatização dos bancos estaduais, acabariam gerando atritos com vários setores políticos, entre eles, o governador de São Paulo, Mário Covas, que era contrário à privatização do Banespa. Na presidência do $\mathrm{BC}$, Arida também enfrentou problemas na área cambial, ao anunciar a criação das "bandas cambiais" de variação máxima e mínima do dólar em relação ao real. $\mathrm{O}$ anúncio da medida provocou uma intensa agitação no mercado de câmbio, em que o BC foi obrigado a intervir para conter os movimentos especulativos. Dias depois, Arida foi acusado de ter vazado informações sobre a valorização do dólar em relação ao real e que teriam beneficiado o seu amigo e ex-sócio no banco BBA-Creditanstalt, Fernão Bracher, que obteve enormes lucros nas operações no mercado de câmbio. No dia 31 de maio de 1995, Arida anunciou a sua saída da presidência do BC. 
Revista NEP, Núcleo de Estudos Paranaenses, Curitiba, v.4, n.2, dez. 2018

Em janeiro de 1996, Arida retornou ao setor privado, tornando-se sócio-diretor da Opportunity Asset Management Ltda., empresa do grupo Opportunity. Em maio de 1997, após a privatização da Vale do Rio Doce, passou a integrar o conselho de administração da ex-estatal, representando o grupo controlado por Daniel Dantas. Em julho de 1998, o banco Opportunity liderou o consórcio vencedor de um dos leilões de privatização do sistema Telebrás, adquirindo o controle da Tele Centro-Sul, de telefonia fixa. Três meses depois, foram divulgadas fitas com ligações telefônicas grampeadas no BNDES, envolvendo o então ministro das Comunicações, Luis Carlos Mendonça de Barros, e o presidente do BNDES, André Lara Resende. As ligações levantaram a suspeita de que o Opportunity fora beneficiado no processo. Após a divulgação do escândalo, Arida deixou o grupo Opportunity e, em 2008, passou a integrar, como sócio, o comitê executivo do BTG, banco de investimentos fundado por André Esteves.

Foi, ainda, membro do conselho de administração do Itaú, do conselho consultivo do Instituto Moreira Salles e do Instituto de Estudos de Política Econômica/Casa das Garças, instituição criada em 2003. Sediada no bairro da Gávea, no Rio de Janeiro e próximo à PUC-RJ, a Casa das Garças reúne economistas e pesquisadores ligados ao PSDB. Arida foi também casado, à época, com Elena Landau, ex-diretora de Desestatização do BNDES, responsável pela condução do processo de privatização de diversas empresas estatais.

Gustavo Loyola ${ }^{8}$ foi o sucessor de Arida na presidência do BC, assumindo o cargo em junho de 1995. Esta seria a segunda vez que Loyola ocupava a presidência da instituição. Natural de Goiânia, Loyola ingressou no curso de Economia da UnB em 1975, tendo-o concluído em 1978. Um ano antes da conclusão do curso, porém, fora admitido em um concurso no banco, onde fez carreira. Apesar de não integrar diretamente o grupo dos economistas-banqueiros da PUC-RJ, aproximava-se desse grupo em função de sua posição em relação à política monetária quando esteve no comando do $\mathrm{BC}$, marcado pela manutenção da valorização do real e pelos juros elevados, remunerando, assim, o capital financeiro.

\footnotetext{
${ }^{8}$ Dicionário Histórico-Biográfico Brasileiro, CPDOC, verbete Gustavo Loyola. PICCOLO, Monica. Reformas Neoliberais... Op. cit., p. 322-325; "Quem é quem no governo”. In: Caros Amigos Reportagem Oficinas de Informações, dezembro de 1998.
} 
Revista NEP, Núcleo de Estudos Paranaenses, Curitiba, v.4, n.2, dez. 2018

Loyola ocupou vários cargos de importância no $\mathrm{BC}$, tendo atuado na área de Mercado de Capitais, chefiado o departamento de Normas Bancárias e, durante a presidência de Francisco Gros, em 1991/1992, foi responsável pela direção de Normas. Em novembro de 1992, logo após o início do processo de impeachment de Collor, o presidente Itamar Franco, convidou-o para assumir o BC no lugar de Gros.

A primeira passagem de Loyola como presidente do BC foi marcada por atritos com o então governador da Bahia, Antônio Carlos Magalhães, por conta de Loyola considerar irregulares diversas agências do Banco do Estado da Bahia (Baneb), abertas sem a autorização em vários municípios baianos. Após também ter divergências com Itamar Franco, Loyola saiu do comando do BC, em março de 1993, sendo substituído por Paulo Cesar Ximenes.

Depois de deixar o banco Loyola trabalhou na MCM Consultores, empresa cujo acionista majoritário era Mailson da Nóbrega, ministro da Fazenda no governo Sarney. Permaneceu na empresa até junho de 1995, quando o ministro Pedro Malan o convidou para assumir, novamente, a presidência do Banco Central, no lugar de Pérsio Arida.

Na sua segunda passagem pela presidência do BC, Loyola defendeu a manutenção das taxa de juros elevadas, a continuação do regime de bandas cambiais, a redução do recolhimento dos compulsórios bancários e a privatização dos bancos estaduais. Loyola também iniciou uma campanha, em conjunto com Malan, destinada a mobilizar os parlamentares governistas a barrar o projeto de lei que limitava os juros reais em $12 \%$ ao ano.

A gestão de Loyola à frente do $\mathrm{BC}$ foi marcada pela reestruturação do sistema bancário brasileiro, a partir da abertura do setor ao capital estrangeiro e da privatização dos bancos estaduais. Neste período, o BC decretou intervenção em grandes instituições bancárias nacionais, entre elas, o Econômico (controlado pelo ex-ministro do governo Geisel, Ângelo Calmon de Sá, principal aliado de ACM na Bahia), o Nacional (instituição mineira pertencente à tradicional família Magalhães Pinto) e o Bamerindus (banco paranaense controlado por José Eduardo de Andrade Vieira, senador, tesoureiro da campanha de FHC em 1994 e ex-ministro da Agricultura). Estas três instituições, a partir da criação do Programa de Reestruturação e Fortalecimento do Sistema Financeiro Nacional (Proer), tiveram o seu controle adquirido por outros bancos. O Econômico foi 
comprado pelo Excel, o Nacional pelo Unibanco e o Bamerindus pelo grupo inglês HSBC. Frente às críticas de que o governo estaria salvando banqueiros falidos, assumindo o rombo de suas instituições e destinando recursos públicos para recuperá-las, Loyola defendeu enfaticamente o Proer, afirmando a necessidade do programa para evitar uma crise bancária semelhante a que ocorrera na Venezuela. Desgastado com as sucessivas crises, como o "escândalo dos precatórios" e o "dossiê da pasta rosa", Loyola deixou a presidência do BC em agosto de 1997. Após a sua saída do governo, Loyola passou também a atuar na iniciativa privada, fundando uma empresa de consultoria sediada em São Paulo.

O sucessor de Loyola no BC foi Gustavo Franco ${ }^{9}$. O seu pai, Guilherme Arinos Lima Verde de Barroso Franco, foi colaborador de Vargas, tendo sido chefe de gabinete de dois ministros da Fazenda: Gastão Vidigal (1946) e Horácio Lafer (1951/1953). Guilherme Franco foi, ainda, colaborador na fundação do BNDE (atual BNDES), em 1952, tendo escrito o seu estatuto e integrado a sua primeira diretoria. Além disso, foi sócio no banco Garantia, vendido em 1998 para o grupo Credit Suisse First Boston.

Assim como outros integrantes da equipe econômica de FHC, Franco cursou, entre 1975 e 1979, o curso de Economia na PUC-RJ. Entre 1981 e 1982, foi professor visitante na FGV-RJ. Em 1982, concluiu o mestrado em Economia também na PUC-RJ, sob a orientação de Winston Fritsch. Sua dissertação conquistou o Prêmio BNDES de Economia e foi publicada em 1983 sob o título de Reforma monetária e instabilidade durante a transição republicana. Em 1984, foi professor visitante no National Bureau of Economic Research. No ano seguinte, também nos EUA, desempenhou a mesma função no Center of European Studies e no Center of International Affairs. Em 1986, concluiu o doutorado em Harvard. Sua tese de doutoramento versava sobre o fenômeno da hiperinflação, ocorrida na Alemanha, Polônia, Áustria e Hungria durante a década de 1920. Também premiada, sua tese foi publicada em 1987 pela Anpec.

Em 1986, ao retornar ao Brasil, Franco tornou-se pesquisador e professor do departamento de Economia da PUC-RJ, onde havia iniciado a sua formação acadêmica.

\footnotetext{
9 Dicionário Histórico-Biográfico Brasileiro, CPDOC, verbete Gustavo Franco. PICCOLO, Monica. Reformas Neoliberais... Op. cit., p. 325-326; "Quem é quem no governo". In: Caros Amigos Reportagem Oficinas de Informações, dezembro de 1998.
} 
Revista NEP, Núcleo de Estudos Paranaenses, Curitiba, v.4, n.2, dez. 2018

Dedicou-se aos estudos sobre inflação e economia internacional. De 1986 a 1993, antes de ingressar no governo, trabalhou, ainda, como consultor de assuntos econômicos.

Filiado ao PSDB, quando FHC ocupava a pasta da Fazenda no governo Itamar, passou a integrar a equipe ministerial por indicação de Pedro Malan, Edmar Bacha e Winston Fritsch, seus colegas da PUC-RJ. Como secretário-adjunto de Política Econômica do ministério da Fazenda, Franco atuou na montagem da secretaria de Política Econômica. Com a posse de Malan na presidência do BC, em setembro de 1993, Gustavo Franco assumiu a diretoria de Assuntos Internacionais, cargo ocupado durante a elaboração do Plano Real, tendo sido um dos idealizadores do padrão bimonetário, que deu origem à URV.

Com a saída de Loyola, em agosto de 1997, Gustavo Franco foi convidado a assumir a presidência do BC. Sua indicação foi considerada uma vitória política do ministro Pedro Malan, uma vez que ela contribuiria para a manutenção da política econômica em curso, especialmente em relação à questão cambial.

Durante o período em que esteve na presidência do $\mathrm{BC}$, a economia nacional sofreu os efeitos de sucessivas crises financeiras, como a crise asiática (1997/1998) e a crise russa (1998), que pressionaram fortemente a posição cambial brasileira. Apesar da grande perda das reservas do país, a política de "âncora cambial" (sobrevalorização da moeda), defendida por Franco, foi mantida por FHC. Porém, ao final do ano de 1997, diante do aumento da recessão e do desemprego, o governo lançou um pacote contendo 51 medidas fiscais e elevou ainda mais a taxa de juros. Na ocasião, Franco cunhou a expressão "saco de maldades" para caracterizar a posição que o BC desempenharia junto ao mercado para defender a valorização do real. Em 1998, foi um dos negociadores, junto com Pedro Malan, de um acordo com o FMI de auxílio econômico ao Brasil no valor de US\$ 41 bilhões.

Após FHC ter assegurado a reeleição, em janeiro de 1999, o governo abandonaria a política de valorização cambial. Os efeitos da crise russa levaram à retirada de bilhões de dólares do país por parte dos investidores estrangeiros. Em face da dificuldade para a manutenção da "âncora cambial", o governo brasileiro decidiu pela desvalorização da moeda o que, para muitos analistas, significou o fim do Plano Real. Um sistema de metas inflacionárias substituiu o regime de bandas cambiais. Além disso, foi colocado em 
prática um compromisso na área fiscal, firmado a partir do acordo com o FMI, pelo qual o governo brasileiro se comprometeria a manter um superávit primário elevado, que garantisse o pagamento da dívida junto ao fundo. A desvalorização do real implicou em um aumento dos juros e da dívida pública, levando o Brasil a uma das mais graves crises de sua história econômica recente. Também surgiram, na época, denúncias de que informações do BC sobre a desvalorização do real teriam sido repassadas para instituições bancárias, que teriam se beneficiado realizando operações no mercado de câmbio, trocando real por dólar. Nesse contexto e sendo alvo de críticas, Gustavo Franco pediu demissão do BC, em janeiro de 1999.

Após deixar o governo, retornou ao quadro docente da PUC-RJ e participou de conselhos de administração de várias empresas. Entre 1999 e 2000, foi professor visitante na universidade de Stanford, nos EUA. Em 2000, fundou a Rio Bravo Investimentos. Em 2001, foi professor visitante na universidade da Califórnia (UCLA). É membro do conselho de governança do Instituto Millenium e, assim como Pérsio Arida, do Instituto de Estudos de Política Econômica/Casa das Garças.

Armínio Fraga ${ }^{10}$ foi o quarto presidente do BC no governo FHC, tendo sucedido Gustavo Franco. Tomou posse no cargo oficialmente em março de 1999 e permaneceu até o fim do governo FHC, em dezembro de 2002.

Fraga nasceu no Rio de Janeiro e estudou no tradicional colégio Santo Inácio, no bairro de Botafogo. Assim como os outros dois presidentes do BC que o precederam, Pérsio Arida e Gustavo Franco, também estudou Economia na PUC-RJ. No mestrado, concluído em 1981, foi aluno de Pedro Malan e de John Williamson. Este último estava no Brasil como professor visitante e foi quem indicou Fraga para o doutorado em economia em Princeton. Após a conclusão do doutorado, em 1985, retornou ao Brasil e ocupou os cargos de economista-chefe e gerente de operações do banco Garantia, do qual o pai de Gustavo Franco era um dos sócios. Neste período, Fraga tornou-se professor da pós-graduação da FGV-RJ e do departamento de Economia da PUC-RJ.

\footnotetext{
10 Dicionário Histórico-Biográfico Brasileiro, CPDOC, verbete Armínio Fraga; "Quem é quem no governo”. In: Caros Amigos Reportagem - Oficinas de Informações, dezembro de 1998.
} 
Revista NEP, Núcleo de Estudos Paranaenses, Curitiba, v.4, n.2, dez. 2018

Em 1988, voltou aos EUA, tornado-se professor visitante do departamento de Finanças da Wharton School, da universidade da Pensilvânia. No ano seguinte, deixou a universidade para assumir a vice-presidência do banco Salomon Brothers.

Em maio de 1991, convidado por Marcílio Marques Moreira, então ministro da Economia, Fazenda e Planejamento do governo Collor, retornou ao Brasil para assumir a diretoria de Operações Internacionais do BC. Porém, com o afastamento de Collor, em 1992, Fraga deixou o cargo e, mais uma vez, retornou para os EUA. Trabalhou por sete anos como diretor-gerente do Soros Fund, fundo de investimentos de George Soros, financista e um dos maiores representantes do capital especulativo internacional. Soros foi responsabilizado pela derrubada da libra esterlina em 1992 e acusado pelo primeiroministro da Malásia de ser o responsável, em julho de 1997, pelos ataques especulativos contra as moedas dos países do Sudeste Asiático.

Em meio à crise que surgida em decorrência da desvalorização do real, Fraga assumiu o BC, substituindo Gustavo Franco. Sua gestão teve como principal objetivo impedir o retorno da inflação no país, operando sob o regime de câmbio flutuante e sistema de metas inflacionárias. Foi Fraga quem utilizou a expressão "a joia da coroa", para se referir ao Banespa quando a instituição foi privatizada, em 2000. Com a vitória de Lula, o novo presidente deixou claro que Fraga não continuaria no governo, fato que se confirmou com a nomeação de Henrique Meirelles para presidir o BC. Entretanto, assim como Fraga, Meirelles tinha uma forte ligação com o capital internacional, tendo sido funcionário de carreira do BankBoston. O anúncio de Meirelles para comandar o BC era um claro indicativo de que o PT não tinha a intenção de estabelecer fortes rupturas com a política econômica do governo FHC.

Após deixar o governo, em agosto de 2003, Fraga criou o fundo Gávea de Investimentos. Em agosto de 2004, voltou a dar aulas na PUC-RJ e, em abril de 2009, assumiu a presidência do conselho de administração da Bovespa. Durante a sua carreira, Fraga trabalhou em diversas instituições financeiras, como JP Morgan e o Unibanco, e foi membro de fóruns internacionais, como o Grupo dos 30, o G-7, que reunia os sete países mais ricos do mundo (posteriormente G-8, em função da entrada da Rússia como nova integrante do grupo), o G-50, que reúne os cinquenta empresários mais bem sucedidos do continente americano, e o Financial Stability Forum. Também atuou em 
Revista NEP, Núcleo de Estudos Paranaenses, Curitiba, v.4, n.2, dez. 2018

organizações não governamentais, como o Instituto Desiderata. Assim como Gustavo Franco, é ligado ao Instituto Millenium e à Casa das Garças.

Durante o governo FHC, outros quatro nomes se destacam no BC, ocupando importantes diretorias dentro da instituição, sendo responsáveis diretos pela condução dos processos de privatização dos bancos estaduais.

Alkimar Moura ${ }^{11}$, graduado em Economia pela UFMG, em 1978, fez mestrado na UCLA (1966) e doutorado na universidade de Stanford (1978). Foi ainda professor visitante, entre janeiro e abril de 1978, da universidade de Berkeley e, desde 1969, é professor do departamento de Economia da FGV-SP. Sua carreira no BC começou em 1987, quando foi diretor da Dívida Pública. Indicado por Edmar Bacha, então assessor especial do ministério da Fazenda e seu amigo desde os tempos em que eram estudantes na UFMG, ocupou entre 1994 e 1996 as diretorias de Normas e Fiscalização e de Política Monetária. Alkimar Moura foi um dos principais defensores e articuladores da privatização dos bancos estaduais enquanto esteve à frente de uma das mais importantes diretorias do BC, junto com Paolo Zaghen ${ }^{12}$, que foi diretor para Assuntos de Reestruturação do Sistema Financeiro Estadual. Doutor em Economia pela universidade de Berkeley (EUA), depois de sair do BC, Zaghen trabalhou ainda no Banco do Brasil, sendo presidente do banco estatal entre 1999 e 2001. Em 2007 tornou-se membro do conselho de supervisão da Bovespa.

Cláudio Mauch ${ }^{13}$, funcionário de carreira do BC, foi diretor de Normas e Fiscalização entre 1995 e 1999, em substituição a Alkimar Moura. A diretoria de Fiscalização era um dos setores mais importantes do $\mathrm{BC}$, sendo o responsável pela avaliação das condições financeiras das instituições bancárias do país. Durante os três anos em que esteve à frente dessa diretoria, conduziu os processos de intervenção e liquidação do Nacional, Econômico e Bamerindus. No caso do Econômico, Mauch foi apontado pelo Ministério Público como um dos responsáveis pela ação tardia do BC, pois o Econômico já estaria quebrado havia pelo menos três anos antes de sua liquidação. Após

\footnotetext{
11 “Saiba quem é Alkimar Moura". In: Folha de S. Paulo, 10/02/1995.

12 "Paolo Zaghen será o novo presidente do BB". In: Gazeta Mercantil, 20/07/1999.

13 "Banco Central completa a nova diretoria". In: Folha de S. Paulo, 11/02/1999.
} 
Revista NEP, Núcleo de Estudos Paranaenses, Curitiba, v.4, n.2, dez. 2018

ter saído do BC, Mauch montou um escritório de consultoria em Porto Alegre, tendo como um de seus clientes o Credit Commercial de France (CCF).

Ou outro importante nome do grupo dos economistas-banqueiros é o de Francisco Lopes ${ }^{14}$, diretor de Política Econômica do BC entre 1995 e 1998. Em janeiro de 1999, antes de Armínio Fraga assumir, chegou a ocupar interinamente a presidência do BC. Seu pai, Lucas Lopes, foi ministro da Fazenda no governo JK e sócio de Roberto Campos na empresa Consultec. Francisco Lopes é formado em Economia pela UFRJ e fez doutorado em Harvard, em 1972. Foi consultor do banco Denasa de Investimentos, superintendente do IPEA e diretor-presidente da empresa de consultoria Macrométrica Pesquisas Econômicas, da qual também foi fundador. Antes de trabalhar no BC foi, em 1986, assessor especial da secretaria de Planejamento e, no ano seguinte, assessor especial do ministério da Fazenda. Juntamente com Edmar Bacha, foi um dos que organizaram o curso de pós-graduação em economia da PUC-RJ, que se transformou num dos mais importantes núcleos de formação dos principais quadros do governo FHC.

Edmar Bacha ${ }^{15}$, juntamente com Pérsio Arida e Fernão Bracher, foi um dos sócio-fundadores do banco BBA-Creditanstalt. Por muitos anos foi economista-chefe do banco criado em 1988 e vendido ao Itaú em 2002. Foi também professor da PUC-RJ, economista do IPEA, presidente do IBGE e assessor especial de FHC no ministério da Fazenda, tendo sido um dos principais nomes na formulação do Plano Real. Foi sua, por exemplo, a ideia da criação do Fundo Social de Emergência (FSE), pelo qual o governo ficava autorizado a remanejar livremente $20 \%$ do orçamento (recursos, principalmente, retirados de programas sociais) e que foi um dos principais instrumentos para a implantação do Plano Real. No governo Sarney, já havia integrado a equipe que formulou o plano de estabilização econômica, batizado de Plano Cruzado.

Bacha também foi presidente do BNDES no início do governo FHC. Representando o BBA-Creditanstlat, participou de vários seminários e encontros nos EUA, destacando a política econômica do governo tucano e as possibilidades de investimentos externos no Brasil, como o que ocorreu em maio de 1998, em Nova Iorque,

\footnotetext{
14 “Quem é quem no governo". In: Caros Amigos Reportagem - Oficinas de Informações, dezembro de 1998.

${ }^{15}$ Dicionário Histórico-Biográfico Brasileiro, CPDOC, verbete Edmar Bacha; “Quem é quem no governo". In: Caros Amigos Reportagem - Oficinas de Informações, dezembro de 1998.
} 
em um evento patrocinado pelo Council of the Americas sobre o tema "A Economia Brasileira e a Crise Asiática", no qual Bacha foi um dos expositores.

Formado em Economia pela UFMG, Bacha estudou doutorado em Yale (EUA), sendo uma espécie de decano do grupo dos economistas-banqueiros ligados ao PSDB, da qual fazem parte Pedro Malan, Gustavo Franco, Pérsio Arida, André Lara Resende, entre outros, e que integraram o departamento de Economia da PUC-RJ onde Bacha foi, juntamente com Francisco Lopes, um dos organizadores de seu curso de pós-graduação. Bacha foi, ainda, professor em diversas universidades norte-americanas, como Yale, Columbia, Harvard e MIT, sendo um dos principais economistas brasileiros que faziam a ponte de ligação entre o Brasil e o pensamento acadêmico neoliberal dos EUA e os organismos financeiros internacionais, como o FMI e o Banco Mundial. Foi Bacha quem, por exemplo, trouxe John Williamson para lecionar na PUC-RJ ao final dos anos 1970.

Após a saída de Luiz Carlos Mendonça de Barros do BNDES, em abril de 1998, para assumir o ministério das Comunicações, a sua presidência passou a ser ocupada por André Lara Resende ${ }^{16}$. Formado em Economia pela PUC-RJ, em 1973, Lara Resende concluiu, dois anos depois, o mestrado pela FGV-RJ. Em 1979, obteve o doutorado pelo MIT. Seu pai, o jornalista Otto Lara Resende, fora diretor da Rede Globo de Televisão e colunista dos jornais $O$ Globo e Folha de S. Paulo.

Ao retornar ao Brasil em 1979 depois de concluir o seu doutoramento, passou a compor o quadro de professores da PUC-RJ, onde havia sido aluno e ao qual ficaria ligado até 1988. Paralelamente as suas atividades docentes, em 1980, Lara Resende tornou-se sócio e diretor-administratico do Garantia. Ficaria no banco até 1985. De 1984 a 1985, foi também diretor-externo da Companhia Ferro Brasileira, cargo que novamente ocuparia no período 1987/1990. Em 1985, escreveu com Pérsio Arida, o famoso artigo Inertial inflation and monetary reform in Brazil.

Entre 1985 e 1986, passou a integrar a equipe do BC, respondendo por questões relativas à dívida pública. Nesse período, durante o governo Sarney, Lara Resende foi, ao lado de Pérsio Arida, Edmar Bacha e dos ministros do Planejamento, João Sayad, e da Fazenda, Dílson Funaro, um dos responsáveis pela elaboração do Plano Cruzado.

\footnotetext{
${ }^{16}$ Dicionário Histórico-Biográfico Brasileiro, CPDOC, verbete André Lara Resende; "Quem é quem no governo". In: Caros Amigos Reportagem - Oficinas de Informações, dezembro de 1998.
} 
Revista NEP, Núcleo de Estudos Paranaenses, Curitiba, v.4, n.2, dez. 2018

Ao sair do governo, Lara Resende retornou ao setor privado, voltando a atuar, entre 1987 e 1988, como diretor do Garantia. Ainda em 1987, foi contratado para trabalhar como diretor-externo das Lojas Americanas. Em 1989, passou a ser diretor-executivo da Brasil Warrant Administrações, do grupo Moreira Salles. Nesse mesmo ano, também passou a ser membro do conselho diretor e vice-presidente executivo do Unibanco, ficando até 1993. A partir de 1990, estreitou sua ligação com o capital internacional ao integrar o conselho executivo do The Capital Group, com sede em Los Angeles. Ficou na empresa norte-americana até 1997.

Em 1993, porém, voltaria ao setor público, sendo convidado por FHC, então titular da pasta da Fazenda no governo Itamar, para ser o negociador-chefe da dívida externa brasileiro no lugar de Pedro Malan, que acabava de assumir a presidência do BC. No mesmo ano, participou da fundação do banco Matrix. Lara Resende também teve grande influência na elaboração do Plano Real, quando FHC ainda era ministro da Fazenda no período Itamar Franco. Com a posse de FHC, afastou-se do Matrix e assumiu o cargo de assessor especial da presidência da República, tendo trabalhado na elaboração do projeto para a reforma da Previdência.

Em abril de 1998, assumiu a presidência do BNDES, em substituição a Luís Carlos Mendonça de Barros, seu sócio no Matrix e que fora designado para ocupar o ministério das Comunicações, após a morte de Sérgio Motta. Permaneceu apenas sete meses no cargo. Em novembro de 1998 foi obrigado a renunciar à presidência do BNDES devido a denúncias, que também derrubaram Luís Carlos Mendonça de Barros do ministério das Comunicações.

Ao deixar mais uma vez o setor público, André Lara Resende atuou, sobretudo, como consultor. A partir de 2002, passou a integrar o conselho de administração do grupo Gerdau e da Metalúrgica Gerdau. Entre 2002 e 2003 foi também pesquisador visitante da St. Antony's College, da universidade de Oxford, na Inglaterra. Em agosto de 2006, recebeu o prêmio de "Economista do Ano" pela Ordem dos Economistas do Brasil. Em agosto de 2009, André Lara Resende passou a compor o Conselho Consultivo Internacional do Itaú Unibanco, presidido por Pedro Malan. Atualmete, trablaha como conselheiro econômico da candidatura à presidência de Marina Silva. 
Revista NEP, Núcleo de Estudos Paranaenses, Curitiba, v.4, n.2, dez. 2018

Francico Gros ${ }^{17}$, substituto de Andrea Calabi no BNDES, nasceu em 1942, no Rio de Janeiro. Foumou-se em Economia pela universidade de Princeton e cursou pósgraduação em Colúmbia, apresentando dissertação sobre os investimentos estrangeiros no Brasil. Em 1967 retornou ao Brasil, começando sua carreira profissional no grupo financeiro Metropolitana, em São Paulo. Em 1972, voltou para os EUA para trabalhar na área internacional da Kideer, Peabody and Company Inc., uma das mais influentes corretoras na Bolsa de Valores de Nova Iorque.

Três anos depois, aceitou o convite do banqueiro Ronaldo César Coelho para assumir uma das diretorias do grupo Multiplic. Em 1977, assumiu o cargo de superintendente de empresas na Comissão de Valores Mobiliários (CVM). Durante a sua permanência na CVM, estreitou laços com Mário Henrique Simonsen, ex-ministro do Planejamento durante o regime militar e então vice-presidente do conselho de administração do grupo Bozano, Simonsen, e com o diplomata Marcílio Marques Moreira, primeiro-secretário do ministério das Relações Exteriores. Em setembro de 1981, deixou a CVM e assumiu o cargo de diretor-executivo do Unibanco, permanecendo até junho de 1985, quando passou a ocupar a diretoria de mercado de capitais do BNDES. Nesse período, supervisionou os primeiros processos de privatização de empresas estatais, como a tecelagem Nova América e a Mafersa. Durante sua permanência no BNDES, aproximou-se de Dílson Funaro, presidente do banco. Em fevereiro de 1987, com Funaro à frente do ministério da Fazenda, aceitou o convite para substituir Fernão Bracher na presidência do BC.

No BC, Gros viajou aos Estados Unidos para iniciar as discussões sobre a moratória da dívida externa brasileira, decretada em 20 de fevereiro de 1987. Os credores internacionais ameaçavam promover ações judiciais que comprometeriam o comércio exterior brasileiro e não mais renovar as linhas de crédito, caso o governo brasileiro insistisse na moratória. Em abril, viajou para Washington junto com o ministro Funaro, para renegociar os termos do pagamento da dívida com o FMI. Viajou também para Nova Iorque, reunindo-se com o comitê dos bancos credores e com representantes das agências de bancos brasileiros no exterior. Em abril de 1987, Dílson Funaro deixou o ministério

${ }^{17}$ Dicionário Histórico-Biográfico Brasileiro, CPDOC, verbete Francisco Gros. 
Revista NEP, Núcleo de Estudos Paranaenses, Curitiba, v.4, n.2, dez. 2018

da Fazenda, sendo substituído por Luís Carlos Bresser Pereira. No mês seguinte, Gros pediu demissão da presidência do BC. Em junho daquele mesmo ano, por indicação do presidente do BNDES, Márcio Fortes, Gros foi eleito pelo conselho administrativo da Aracruz Celulose para ocupar a presidência da empresa, que contava com participação acionária do BNDES. Nos dois anos em que presidiu a Aracruz Celulose, Gros negociou a venda de ações da empresa que estavam sob o poder do banco e a consequente ampliação do setor privado no seu controle acionário. Em junho de 1989, deixou a presidência da Aracruz Celulose, ocupando em seguida a presidência do BFC Banco, tendo permanecido no cargo até maio de 1991, quando foi indicado por Marcílio Marques Moreira, ministro da Economia do governo Collor, para ocupar pela segunda vez a presidência do BC.

Ao assumir novamente o BC, em substituição a Ibrahim Eris, destacou, no discurso de posse, a defesa da independência da instituição e a redução de suas atribuições, que deveriam ser limitadas à fiscalização da moeda, do crédito e do câmbio.

Em 30 de setembro de 1992, no dia seguinte da aprovação pelo Congresso para a abertura do processo de impeachment de Collor, Francisco Gros entregou sua carta de demissão ao ministro Marcílio Marques Moreira. Porém, ao assumir a presidência da República, Itamar Franco confirmou a sua permanência no cargo. Em outubro do mesmo ano, no entanto, voltou a pedir demissão por discordar dos rumos da política econômica do governo, principalmente depois das críticas de Itamar sobre a política monetária do $\mathrm{BC}$, em especial pela manutenção das taxas de juros reais e positivas. Em novembro daquele ano, deixaria a presidência do BC, sendo substituído por Gustavo Loyola. Em 1993, assumiu o cargo de diretor-executivo do Morgan Stanley, em Nova Iorque, ficando responsável pela área da América Latina. Em 1997, por decisão do Morgan Stanley, Gros retornou ao Brasil, pois o banco norte-americano estava interessado em participar das privatizações brasileiras.

Em fevereiro de 2000, assumiu a presidência do BNDES, substituindo Andréa Calabi. Defensor do processo de abertura da economia brasileira, bem como das privatizações, permaneceu à frente do BNDES até dezembro de 2001. Em janeiro de 2002, assumiu a presidência da Petrobrás então ocupada por Henri Philippe Reichstul. 
Revista NEP, Núcleo de Estudos Paranaenses, Curitiba, v.4, n.2, dez. 2018

Ao sair do governo, Gros assumiu os cargos de diretor-presidente e membro dos conselhos de administração da Fosfertil e da Ultrafertil. Tornou-se presidente do conselho de administração da Lojas Renner, membro dos conselhos de administração da Globex Utilidades, Ocean Wilsons, Energias do Brasil e Amcham - Câmara Americana de Comércio. Também foi membro dos conselhos consultivos da Air Liquide do Brasil, Scania Latin America, banco Financia, Brazilian American Chamber of Commerce, The Americas Society Inc. e The Nature Conservancy. Participou, ainda, do conselho de administração da OGX, empresa de petróleo e gás do grupo EBX de Eike Batista.

Eleazar de Carvalho Filho $^{18}$ foi o último dos presidentes a ocupar o BNDES no governo FHC. Realizou sua formação acadêmica dos EUA. Em 1979, graduou-se em Economia pela universidade de Nova Iorque. Dois anos depois, realizou o mestrado em relações internacionais pela universidade Johns Hopkins. Completou os estudos, em 1998, com o doutorado pela Harvard Business School.

Em 1981, tornou-se assessor do banco Citibank/Crefisul de Investimento e, posteriormente, assumiu o cargo de diretor-adjunto da área internacional, função que exerceu até 1983. Entre 1986 e 1992, ocupou diversos cargos na Alcoa Alumínio. Primeiramemte, como diretor da área financeira e, posteriormente, como vice-presidente do Instituto Cultural da Alcoa e como superintendente da Alcoa Previ, na qual foi responsável pela seguradora e pela corretora de seguros. Em 1992 voltou a trabalhar em instituições financeiras, chefiando a área de finanças corporativas do banco Garantia, em São Paulo. Em 1994 passou a dirigir o escritório do banco no Rio de Janeiro, permanecendo até 1998, quando se transferiu para o banco suíço Warburg Dillon Read.

Em abril de 2000, foi convidado por Francisco Gros para a integrar a equipe do BNDES, assumindo o cargo de diretor superintendente do BNDES Participações (BNDESpar). Em seguida, foi nomeado diretor da Secretaria Geral de Apoio à Desestatização, respondendo pelas operações e serviços de privatização, assim como pela diretoria da área de Produtos Estruturados.

Após a saída de Francisco Gros para assumir presidência da Petrobras em janeiro de 2002, Eleazar Filho assumiu a presidência do BNDES. Durante sua gestão, manteve

\footnotetext{
${ }^{18}$ Dicionário Histórico-Biográfico Brasileiro, CPDOC, verbete Eleazar de Carvalho Filho.
} 
o modelo iniciado na administração anterior. Permaneceu à frente do banco até dezembro de 2002.

Em 2003, voltou a trabalhar em instituições financeiras privadas, tornando-se sócio fundador da Iposeira Gestão de Ativos. Em 2005, foi designado conselheiro da Varig e, posteriormente, ocupou a vice-presidência do conselho de administração da empresa. Ao retornar às suas atividades na Iposeira assumiu, em junho de 2006, a presidência da BHP-Billiton do Brasil. Com a compra de parte do capital da Iposeira pelo Unibanco, chefiou a estruturação do Unibanco Banco de Investimento, resultado da fusão da Iposeira com o grupo Unibanco. Em fevereiro de 2009, com a fusão entre o Itaú e o Unibanco, o Unibanco Banco de Investimento foi extinto e Eliasar Filho deixou a instituição. Em maio de 2009, passou a integrar o comitê especial independente do conselho de administração da Aracruz. Foi ainda membro dos conselhos administrativos e consultivos do ABN Amro Brasil, da Telemar, da Vale do Rio Doce, da Eletrobrás e da São Paulo Alpargatas.

Elena Landau ${ }^{19}$ foi outro importante nome dentro do BNDES, tendo ocupado, até junho de 1996, a diretoria de Desestatização, uma das mais importantes do banco. Assessora econômica do PSDB, foi casada com Pérsio Arida, ex-presidente do BC e exsócio do grupo Opportunity, que participou ativamente nas privatizações do governo FHC. Elena Landau trabalhou como consultora do banco norte-americano Bear Stearns, especialmente em assuntos referentes a privatizações no Brasil e na América Latina. $\mathrm{O}$ Bear Stearns, inclusive, participou da privatização da Usiminas na época em Elena Landau era diretora de Desestatização do BNDES. Landau coordenou a venda de diversas estatais, entre elas a Usiminas e a Light, e foi a responsável, por exemplo, pela elaboração do modelo de privatização da Vale do Rio Doce. Respondendo às acusações de que ao trabalhar para empresas privadas estaria se beneficiando de informações privilegiadas obtidas como diretora do BNDES, disse ser "muito comum" a situação de funcionários saídos do governo trabalhem para o setor privado.

19 "Quem é quem no governo". In: Caros Amigos Reportagem - Oficinas de Informações, dezembro de 1998. 
Revista NEP, Núcleo de Estudos Paranaenses, Curitiba, v.4, n.2, dez. 2018

Edward Amadeo $^{20}$ foi ministro do Trabalho entre 1998 e 1999 e, entre 1999 e 2001, foi secretário de Política Econômica do ministério da Fazenda. Fez doutorado em Harvard e, com sua entrada no governo a partir de 1998, ampliou o grupo de economistasbanqueiros saídos da PUC-RJ, onde era professor. Ao tomar posse no ministério, propôsse a desempenhar duas tarefas: avançar na reforma trabalhista, ou seja, na retirada de direitos dos trabalhadores e na precarização das relações de trabalho, e no aumento da "empregabilidade do trabalhador brasileiro". Ficou famosa uma de suas primeiras declarações públicas enquanto ministro em que disse não existir problema sério de desemprego no país.

Eliana Cardoso ${ }^{21}$ foi secretária de Assuntos Internacionais do ministério da Fazenda no início do governo FHC. Doutora em Economia pelo MIT, Eliana Cardoso trabalhou como economista-chefe e assessora especial no Banco Mundial e como conselheira do departamento de Pesquisas do FMI. Foi casada com o banqueiro Edmar Bacha, um dos formuladores do Plano Real, e com o consultor internacional e economista do MIT, Rudiger Dornbusch. Foi, ainda, professora de diversas universidades norteamericanas, entre elas, Yale e MIT. Foi Eliana Cardoso quem apresentou, junto com Daniel Dantas, o panorama sobre o Brasil na reunião em novembro de 1989, patrocinada pelo FMI, Banco Mundial, BID e o governo norte-americano e que firmaria o chamado “consenso de Washington".

\section{Quadro: Principais nomes do grupo dos economistas-banqueiros}

\begin{tabular}{|c|c|c|}
\hline Nome & Cargo ocupado no governo FHC & $\begin{array}{c}\text { Formação acadêmica } \\
\text { (doutorado) }\end{array}$ \\
\hline Pedro Malan & Ministro da Fazenda (1995/2002) & Berkeley (EUA) \\
\hline Pérsio Arida & Presidente do BC (1995) & MIT (EUA) \\
\hline Gustavo Loyola & Presidente do BC (1995/1997) & FGV-RJ \\
\hline Gustavo Franco & Presidente do BC (1997/1998) & Harvard (EUA) \\
\hline Armínio Fraga & Presidente do BC (1999/2002) & Princeton (EUA) \\
\hline Alkimar Moura & Diretor do BC (1994/1996) & Stanford (EUA) \\
\hline
\end{tabular}

20 Dicionário Histórico-Biográfico Brasileiro, CPDOC, verbete Edward Amadeo; "Quem é quem no governo". In: Caros Amigos Reportagem - Oficinas de Informações, dezembro de 1998.

21 "Quem é quem no governo". In: Caros Amigos Reportagem - Oficinas de Informações, dezembro de 1998. 
Revista NEP, Núcleo de Estudos Paranaenses, Curitiba, v.4, n.2, dez. 2018

\begin{tabular}{|c|c|c|}
\hline Paolo Zaghen & Diretor do BC (1996/1999) & Berkeley (EUA) \\
\hline Cláudio Mauch & Diretor do BC (1995/1999) & - \\
\hline Francisco Lopes & Diretor do BC (1995/1996) & Yale (EUA) \\
\hline Edmar Bacha & Presidente do BNDES (1995) & MIT (EUA) \\
\hline $\begin{array}{c}\text { André Lara } \\
\text { Resende }\end{array}$ & Presidente do BNDES (1998) & Columbia (EUA) $^{*}$ \\
\hline $\begin{array}{c}\text { Francisco Gros } \\
\text { Eleazar de } \\
\text { Carvalho Filho }\end{array}$ & Presidente do BNDES (2000/2001) & Harvard (EUA) \\
\hline Elena Landau & Presidente do BNDES (2002) & PUC-RJ \\
\hline Edward Amadeo & Ministro do Trabalho (1998/1999) & Harvard (EUA) \\
\hline Eliana Cardoso & Secretária do ministério da Fazenda (1995) & MIT (EUA) \\
\hline
\end{tabular}

* Mestrado

Fonte: "Quem é quem no governo". In: Caros Amigos Reportagem - Oficinas de Informações, dez. de 1998; GUIOT, André Pereira. Um “moderno príncipe” para a burguesia brasileira: o PSDB (1988-2002). Dissertação (Mestrado em História Social). Programa de Pós-Graduação em História Social, Universidade Federal Fluminense, Niterói, 2006, p. 201.

\section{Bibliografia}

ABREU, Alzira Alves de; Et. al. (Coord.). Dicionário Histórico-Bibliográfico Brasileiro pós 1930. Rio de Janeiro: FGV/CPDOC, 2001, 5 vol.

BIANCHI, Álvaro (Org.). A crise brasileira e o governo FHC. São Paulo: Xamã, 1997.

CHESNAIS, François. A mundialização do capital. São Paulo: Xamã, 1996.

FILGUEIRAS, Luiz. História do Plano Real: fundamentos, impactos e contradições. São Paulo: Boitempo, 2000.

FIORI, José Luis. Os moedeiros falsos. Petrópolis: Vozes, 1997.

GUIOT, André Pereira. Um "moderno príncipe" para a burguesia brasileira: o PSDB (1988-2002). Dissertação (Mestrado em História Social). Programa de Pós-Graduação em História Social, Universidade Federal Fluminense, Niterói, 2006.

LESBAUPIN, Ivo (Org.). O Desmonte da Nação: balanço do governo FHC. Petrópolis, Vozes, 1999. 
NEP Revista NEP, Núcleo de Estudos Paranaenses, Curitiba, v.4, n.2, dez. 2018

PICCOLO, Monica. Reformas Neoliberais no Brasil: a privatização nos governos Fernando Collor e Fernando Henrique Cardoso. Tese (Doutorado em História). Programa de Pós-Graduação em História da Universidade Federal Fluminense, Niterói, 2010.

Recebido: 2 ago. 2018

Aceito: 24 set. 2018 